\title{
Degradabilidade in situ do bagaço de cana-de-açúcar para pequenos ruminantes de raças naturalizadas do Nordeste brasileiro
}

\author{
[In situ degradability of sugarcane bagasse for naturalized small ruminant breeds \\ from the northeastern Brazil] \\ G.M.F. Gomes ${ }^{1}$, A.M. Vasconcelos ${ }^{1}$, A.S. Egito ${ }^{2}$, A.R. Lima $^{2}$, J.C. Carneiro ${ }^{3}$, \\ A.V. Landim ${ }^{1}$, N.L.O. Fonteles ${ }^{1}$, H.O. Salles ${ }^{2}$ \\ ${ }^{1}$ Universidade Estadual Vale do Acaraú - Sobral, CE \\ ${ }^{2}$ Embrapa Caprinos e Ovinos -Sobral, CE \\ ${ }^{3}$ Embrapa Gado de Leite - Juiz de Fora, MG
}

\begin{abstract}
RESUMO
Com o crescimento da indústria sucroalcooleira, buscam-se alternativas de uso dos resíduos gerados por ela. Os pequenos ruminantes de raças naturalizadas do Nordeste brasileiro mostram-se como grupos potenciais para que seja utilizado o bagaço de cana-de-açúcar (BCA) nas dietas. Nesse contexto, objetivou-se determinar a degradabilidade ruminal in situ da matéria seca (MS) e da fibra em detergente neutro (FDN) do BCA e os parâmetros ruminais em caprinos Moxotó e ovinos Morada Nova, fistulados no rúmen. Contidos em sacos de náilon, $3 \mathrm{~g}$ de $\mathrm{BCA}$ foram incubados no rúmen nos tempos seis, 24 e 96 horas, determinando-se o conteúdo de MS e FDN nos resíduos obtidos. Nos tempos zero, seis e 12 horas após a primeira refeição, mediram-se no líquido ruminal $\mathrm{pH}$ e nitrogênio amoniacal $\left(\mathrm{N}-\mathrm{NH}_{3}\right)$ ruminal. $\mathrm{O}$ CMS não diferiu entre caprinos e ovinos. O potencial de máxima degradação da MS foi semelhante entre espécies, e da FDN foi superior em caprinos. Ovinos apresentaram maiores tempo de colonização, taxa de degradação e degradabilidade efetiva da MS e FDN. O pH não diferiu entre as espécies. Observou-se maior concentração de $\mathrm{N}-\mathrm{NH}_{3}$ ruminal em caprinos, no tempo zero. Diante da maior velocidade de degradação da MS do BCA pelos ovinos, essa espécie se mostra detentora de uma microbiota ruminal com crescimento mais eficiente sobre o BCA.
\end{abstract}

Palavras-chave: fibra, resíduo, rúmen, caprinos, ovinos

\begin{abstract}
With the increase of the sugar and alcohol industries, alternative uses for residue are sought, and the small ruminants from the naturalized breeds of northeastern Brazil are potential groups to make use of the sugarcane bagasse (SCB) in their diets. In this context, the objective was to determine the in situ degradability of dry matter (DM) and neutral detergent fiber (NDF) of SCB and ruminal parameters in Moxotó goats and Morada Nova sheep rumen fistulated. Three grams of SCB were placed in naylon bags and incubated in the rumen at 6, 24 and 96 hours, and the residues analyzed for DM and NDF. Rumen fluid was collected at zero, 6 and 12 hours after the first meal and $\mathrm{pH}$ and ammonia nitrogen $\left(\mathrm{N}-\mathrm{NH}_{3}\right)$ were determined. DMI did not differ between goats and sheep. The maximum degradation potential of $D M$ was similar between species and the A of NDF was higher in goats. Sheep had higher colonization time, rate of degradation and effective degradability of DM and NDF. The pH did not differ between species. The highest concentration of ruminal $\mathrm{N}-\mathrm{NH}_{3}$ in goats was at time zero. Given the higher rate of degradation of bagasse dry matter by sheep, this specie shows a more efficient rumen microbial growth on $S C B$.
\end{abstract}

Keywords: fiber, residue, rumen, goat, sheep

Recebido em 16 de abril de 2012

Aceito em 15 de março de 2013

E-mail: gilmariofg@yahoo.com.br 


\section{INTRODUÇÃO}

O bagaço de cana-de-açúcar é um alimento que apresenta como principais características elevado conteúdo em constituintes da parede celular, baixa digestibilidade e baixo teor de proteína bruta. Apesar de suas limitações nutricionais, trata-se de uma fonte de fibra importante para manter a saúde ruminal. Seu baixo teor em proteína leva à necessidade de correções nutricionais em dietas à base de bagaço de canade-açúcar (Pinto et al., 2003).

Tratamentos químico e físico geralmente são utilizados objetivando melhorar o valor nutritivo do bagaço de cana-de-açúcar (Pires et al., 2006; Rabelo et al., 2008). Dentre esses métodos, destacam-se o do uso do hidróxido de sódio e o do uso da amônia. No entanto, são métodos que, além de apresentarem custo elevado e manejo difícil (Carneiro et al., 1998), podem trazer riscos à saúde e ao meio ambiente, tornando-se muitas vezes inviável seu emprego na propriedade rural. Nesse sentido, chama-se atenção para algumas espécies de pequenos ruminantes adaptadas a regiões áridas e semiáridas. As espécies mencionadas já possuem, em sua microbiota digestiva, espécies que degradam a fração fibrosa, porém estas, devido a um processo adaptativo, passam a vir a ser mais eficientes nessa degradação. Dessa maneira, torna-se importante o conhecimento do processo digestivo desses animais, considerados, na atualidade, fontes potenciais de microorganismos e enzimas para produção de etanol de segunda geração (Cunha et al., 2011).

Neste contexto, objetivou-se determinar a degradação ruminal, pela técnica in situ de incubação em sacos de náilon, da matéria seca (MS) e da fibra em detergente neutro (FDN), do bagaço de cana-de-açúcar (BCA), bem como os parâmetros ruminais, o $\mathrm{pH}$ e o nitrogênio amoniacal $\left(\mathrm{N}-\mathrm{NH}_{3}\right)$, em caprinos e ovinos de raças naturalizadas do Nordeste brasileiro.

\section{MATERIAL E MÉTODOS}

Este experimento foi conduzido na Embrapa Caprinos e Ovinos, localizada no município de Sobral-CE, no período de julho a agosto de 2009. Foram utilizadas duas espécies de ruminantes (caprina e ovina), sendo três caprinos da raça Moxotó e três ovinos da raça Morada Nova, todos machos, fistulados no rúmen, com peso vivo médio de $21 \mathrm{~kg}$ e idade aproximada de 12 meses, mantidos em gaiolas metabólicas de madeira com bebedouro, comedouro e saleiro. $\mathrm{O}$ período experimental foi composto de 19 dias, sendo 14 dias para adaptação dos animais às dietas experimentais e às instalações e cinco dias para coleta de dados. Todas as dietas foram formuladas para serem isoproteicas, isofibrosas e isoenergéticas. Estas foram oferecidas em duas refeições diárias, às oito e às 14 horas. As sobras foram quantificadas diariamente para ajuste e determinação do consumo voluntário, proporcionando $10 \%$ de sobras. O consumo de MS foi determinado em gramas/dia (g/dia), em porcentagem do peso corporal (\%PC) e em gramas/unidade de tamanho metabólico (g/UTM). A relação volumoso:concentrado foi 53,56:46,44. As fontes volumosas utilizadas foram o feno de capim tifton 85 (Cynodon sp.) e o bagaço de cana-de-açúcar seco ao sol. O concentrado foi formulado à base de milho e farelo de soja (Tab. 1).

Tabela 1. Composição centesimal e química da dieta experimental expressa em porcentagem da matéria seca (\%MS)

\begin{tabular}{lc}
\hline Alimentos & MS (\%) \\
\hline Bagaço de cana-de-açúcar & 23,56 \\
Feno tifton 85 & 30,00 \\
Milho (grão) & 35,98 \\
Farelo de soja & 9,93 \\
Fosfato bicálcico & 0,521 \\
Calcário calcítico & 0,015 \\
Total & 100,00 \\
\hline Composição em nutrientes (Base MS) & \\
\hline Proteína bruta & 11,26 \\
Fibra em detergente neutro & 47,61 \\
Energia metabolizável (Mcal/kg) & 2,21 \\
Extrato etéreo & 2,33 \\
Cálcio & 0,33 \\
Fósforo & 0,30 \\
\hline
\end{tabular}

Foi colhida uma amostra composta do bagaço de cana-de-açúcar (500g), que foi submetida à secagem em estufa de ventilação forçada, por temperatura de $65^{\circ} \mathrm{C}$ por 48 horas para a determinação da matéria pré-seca. Em seguida, as amostras foram processadas em moinho dotado de peneira com malha de $5 \mathrm{~mm}$. Três gramas desse bagaço foram incubados em sacos de náilon com dimensões de $13 \times 5 \mathrm{~cm}$ e porosidade aproximada em $60 \mu \mathrm{m}$. Os sacos foram secos em estufa a $65^{\circ} \mathrm{C}$ por $24 \mathrm{~h}$, colocados em dessecador por 30 minutos e pesados, 
obtendo-se o peso vazio (peso do saco sem amostra). A composição química do bagaço de cana-de-açúcar é apresentada na Tab. 2.

Tabela 2. Composição química do bagaço de cana-de-açúcar expressa em porcentagem da matéria seca (\%MS), incubado no rúmen de caprinos e ovinos

\begin{tabular}{lc}
\hline Componente & $\begin{array}{c}\text { Bagaço de } \\
\text { cana-de-açúcar }\end{array}$ \\
\hline Matéria seca & 89,07 \\
Proteína bruta & 3,78 \\
Extrato etéreo & 1,54 \\
Fibra em detergente neutro & 80,02 \\
Fibra em detergente ácido & 51,17 \\
Hemicelulose & 28,85 \\
Celulose & 40,45 \\
Lignina & 10,72 \\
Cinzas & 2,30 \\
\hline
\end{tabular}

Os tempos de incubação foram seis, 24 e 96 horas (Sampaio, 1988). O tempo zero $\left(\mathrm{t}_{0}\right)$ foi obtido por meio da lavagem do material em água corrente. O número de réplicas foi de três para os tempos seis e 24 horas, quatro réplicas para 96 horas e seis para $\mathrm{o} \mathrm{t}_{0}$. As réplicas referentes a cada tempo, exceto $\mathrm{o}_{0}$, foram colocadas no rúmen dentro de saco de náilon medindo $20 \times 10 \mathrm{~cm}$ com uma corrente âncora de $10 \mathrm{~cm}$ e peso de $300 \mathrm{~g}$ para manter os sacos submersos no conteúdo ruminal.

Utilizou-se incubação do tipo reversa, para que todos os saquinhos fossem retirados e lavados ao mesmo tempo, e, assim, fosse retirado o efeito de lavagem das fontes de variação. Após, os sacos foram imersos em água com gelo por 30 minutos para diminuir a atividade microbiana. Em seguida, foram lavados em água corrente até esta sair límpida. Posteriormente, os sacos foram colocados em estufa de ventilação forçada, em temperatura de $65^{\circ} \mathrm{C}$ por 24 horas para secagem, e, então, foram pesados. O material residual foi processado e moído em peneira de malha de $1 \mathrm{~mm}$ e colocado em frascos identificados para posterior análise de MS e FDN (Association..., 1995).

O desaparecimento da MS e da FDN foi calculado por diferenças de pesos, antes e após a incubação ruminal, e expresso em porcentagem. Os dados observados do desaparecimento da MS e da FDN nos tempos seis, 24 e 96 horas foram usados para estimar os parâmetros de degradabilidade ruminal com base na equação exponencial de Mehrez e Ørskov (1977), simplificada por Sampaio (1988). Os horários em que a taxa de degradação foi inferior ao $t_{0}$ não foram utilizados para obtenção da equação. Com os parâmetros estimados do modelo anterior, estimou-se o tempo de colonização (TC) conforme preconizado por McDonald (1981). Para determinação da degradabilidade efetiva (DEf), utilizou-se a fórmula descrita por Ørskov e McDonald (1979). Os valores teóricos da taxa de passagem do bagaço de cana-de-açúcar no rúmen foram: (k): 2, 6 e $8 \%$.

Ao $25^{\circ}$ dia, foi realizada a coleta de líquido ruminal para determinação do $\mathrm{pH}$ e $\mathrm{N}-\mathrm{NH}_{3}$, nos tempos zero (antes da alimentação), seis e 12 horas após a primeira refeição. O líquido ruminal foi filtrado e transferido para tubos falcon. A determinação do $\mathrm{pH}$ ruminal foi realizada utilizando-se potenciômetro digital no momento da coleta do líquido ruminal. Para análises de N$\mathrm{NH}_{3}$ ruminal, transferiu-se uma alíquota de $40 \mathrm{~mL}$ do líquido ruminal de cada período para os tubos contendo $1,0 \mathrm{~mL}$ de ácido sulfúrico a $50 \%$, conservados a $-18^{\circ} \mathrm{C}$. Posteriormente, as amostras foram descongeladas e $\quad \mathrm{O} \quad \mathrm{N}-\mathrm{NH}_{3}$ ruminal foi determinado por destilação com óxido de magnésio, usando-se ácido bórico com indicador misto de cor como solução receptora, e titulação com ácido clorídrico $0,01 \mathrm{~N}$.

Os efeitos entre espécie sobre o consumo de matéria seca foram submetidos à análise de variância, com comparação de médias pelo teste de Duncan, ao nível de significância de 5,0\%. O delineamento experimental adotado para o ensaio in situ foi o em blocos ao acaso com parcelas subdivididas, sendo os animais os blocos, os tempos de incubação as parcelas e o alimento a subparcela. Os dados utilizados (observados) para estimativa dos parâmetros de degradação foram analisados por espécie e processados pelo método interativo, utilizando-se o procedimento NLIN do pacote estatístico SAS (Statistical..., 2009) para modelos não lineares. Os efeitos entre espécie e dentro de espécie sobre o desaparecimento da MS e da FDN do bagaço de cana-de-açúcar foram submetidos à análise de variância, com comparação de médias pelo teste de Tukey, ao nível de significância de 5,0\%, referente ao efeito entre espécie, e pelo teste $t$, ao nível de significância de $0,01 \%$, referente ao efeito dentro de cada espécie. Em relação aos parâmetros de fermentação ruminal, os dados 
obtidos nos tempos zero, seis e 12 horas foram submetidos a um esquema fatorial 2 (espécies) $\mathrm{x}$ 3 (tempos), utilizando-se software Statistical Analysis System - SAS (versão 9.2), com aplicação do teste de médias de Duncan ao nível de significância de 5,0\%.

\section{RESULTADOS E DISCUSSÃO}

O consumo de matéria seca (CMS) não diferiu entre as espécies, independentemente da forma como foi expresso $(\mathrm{P}<0,05)$ (Tab. 3). $\mathrm{O}$ consumo médio de MS foi de 460,00g/dia, equivalente a $2,20 \%$ do PC e a 47,10g/UTM. O uso de animais de categoria e peso semelhantes recebendo a mesma dieta explica o efeito não significativo entre espécies sobre o CMS. Caprinos e ovinos diferem na sua fisiologia e anatomia digestiva, fatores que devem ser considerados no estudo entre diferentes espécies. No caso de maior CMS por caprinos, as justificativas abordam ciclo de ruminação mais longo e maior eficiência de redução no tamanho de partícula, proporcionando maior taxa de degradação e rápida taxa de passagem (García et al., 1995). A seletividade é outro aspecto que pode influenciar o consumo voluntário. Na literatura, já é bem conhecido o poder seletivo de caprinos, no entanto existem evidências de que caprinos e ovinos naturalizados do Nordeste brasileiro em condições de caatinga apresentem padrão semelhante de seletividade Pfister e Malechek (1986). Isto pode explicar, em parte, o efeito não significativo sobre CMS.

Tabela 3. Consumo de matéria seca (CMS) em caprinos e ovinos alimentados com rações contendo bagaço de cana-de-açúcar

\begin{tabular}{lccc}
\hline \multirow{2}{*}{ Variáveis } & \multicolumn{2}{c}{ Espécie } & \multirow{2}{*}{ CV $(\%)$} \\
\cline { 2 - 3 } & Caprina & Ovina & \\
\hline CMS (kg/dia) & $520,00 \mathrm{a}^{*}$ & $400,00 \mathrm{a}$ & 18,32 \\
CMS (\% PC) & $2,48 \mathrm{a}$ & $1,92 \mathrm{a}$ & 18,08 \\
CMS (g/UTM) & $53,17 \mathrm{a}$ & $41,04 \mathrm{a}$ & 18,14 \\
\hline
\end{tabular}

*Letras diferentes na linha diferem entre espécies pelo teste de Duncan $(\mathrm{P}<0,05)$.

Apesar da semelhança para o CMS, a cinética de degradação ruminal diferiu entre as espécies, sendo observada uma maior taxa de degradação da MS (Tab. 5) em ovinos, o que proporcionou um maior desaparecimento da MS do BCA nos tempos 24 e 96 horas $(\mathrm{P}<0,05)$ (Tab. 4). O consumo voluntário está diretamente relacionado com a taxa de digestão e de passagem, no entanto essa relação não foi estabelecida nas condições deste estudo. Segundo Morand-Fehr (2005), não tem ocorrido diferença no tempo de retenção médio de partículas de alimentos no trato digestivo de ovinos e caprinos alimentados com forragens de boa qualidade, entretanto o tempo de retenção em caprinos recebendo forragens de pior qualidade é longo. Isto é corroborado por Carneiro (1994), que, ao trabalhar com alimento de baixa qualidade (palha de soja), observou menor consumo em $\mathrm{g} / \mathrm{kg}^{0,75}$ de MS (35,60 vs. 55,76), ++FDN $(25,02$ vs. 39,49) e FDA $(19,11$ vs. 30,35) para caprinos em relação aos ovinos.

Tabela 4. Desaparecimento da matéria seca (MS) e da fibra em detergente neutro (FDN) do bagaço de cana-de-açúcar em caprinos e ovinos, em função do tempo de incubação no rúmen

\begin{tabular}{l|rrrc}
\hline \multirow{2}{*}{ Horas } & \multicolumn{3}{c}{ Espécie } & \multicolumn{2}{c}{ Espécie } \\
\cline { 2 - 5 } & Caprina & Ovina & Caprina & FDN $(\%)$ \\
\hline 6 & \multicolumn{2}{c}{ MS (\%) } & $10,31 \mathrm{Aa}^{*}$ & $8,72 \mathrm{Ba}$ \\
24 & $15,40 \mathrm{Aa}^{*}$ & $15,40 \mathrm{Aa}$ & $16,28 \mathrm{Ab}$ & $17,37 \mathrm{Bb}$ \\
96 & $19,74 \mathrm{Ab}$ & $24,57 \mathrm{Bb}$ & $28,39 \mathrm{Ac}$ & $29,32 \mathrm{Bc}$ \\
\hline
\end{tabular}

"Letras diferentes, maiúsculas na linha $(\mathrm{P}<0,05)$ e minúsculas na coluna $(\mathrm{P}<0,0001)$, diferem entre espécies e tempos pelo teste de Tukey e t, respectivamente.

A porcentagem de desaparecimento da MS do BCA, em cada espécie animal, aumentou com o maior horário de incubação ruminal $(\mathrm{P}<0,05)$. Isto ocorreu porque o alimento ficou mais tempo sofrendo ação das enzimas microbianas.
Os dados observados de desaparecimento da FDN do BCA diferiram entre $(\mathrm{P}<0,05)$ e dentro de cada espécie no tempo $(\mathrm{P}<0,0001)$. Para os caprinos, no tempo de seis horas de incubação, houve maior degradação da FDN, o que explica 
os maiores valores estimados na curva de degradação da FDN, até o tempo de incubação de oito horas (Fig. 2), no entanto, nos tempos 24 e 96 horas, houve efeito semelhante ao da MS com maior degradação em ovinos. Efeito semelhante ao da MS também foi observado para a porcentagem de desaparecimento da FDN dentro de cada espécie. Pode-se observar, portanto, que a microbiota ruminal dos ovinos provavelmente foi mais eficiente em utilizar os nutrientes oriundos do BCA.

Os parâmetros de degradação ruminal e de degradabilidade efetiva da MS e da FDN do BCA em caprinos e ovinos são apresentados na Tab. 5 .

Tabela 5. Parâmetros de degradação ruminal e de degradabilidade efetiva (DEf) para as taxas de passagem 2, 6 e 8\%/h da matéria seca (MS) e da fibra em detergente neutro (FDN) do bagaço de cana-deaçúcar em caprinos e ovinos

\begin{tabular}{lccccc}
\hline \multirow{2}{*}{ Variáveis } & \multicolumn{3}{c}{ Espécie } & \multicolumn{2}{c}{ Espécie } \\
\cline { 2 - 6 } & Caprina & Ovina & Caprina & Ovina \\
\cline { 2 - 5 } & & MS & 33,82 & 31,36 \\
A $(\%)^{1}$ & 35,08 & 34,15 & 1,6 & 2,7 \\
$\mathrm{c}(\% / \mathrm{h})^{1}$ & 1,4 & 3,7 & 7,41 & 7,41 \\
$\mathrm{~S}(\%)$ & 11,70 & 11,70 & $-0,49$ & 1,69 \\
TC (horas) & $-2,81$ & 0,52 & 19,05 & 22,63 \\
DEf $(2 \% / \mathrm{h})^{2}$ & 20,43 & 26,98 & 12,95 & 15,62 \\
DEf $(6 \% / \mathrm{h})^{2}$ & 15,70 & 20,70 & 11,80 & 14,08 \\
DEf $(8 \% / \mathrm{h})^{2}$ & 14,85 & 19,16 & & FDN \\
\hline
\end{tabular}

${ }^{1}$ Parâmetros da equação para estimar a degradação (d) em um determinado tempo (t): Deg = A - B exp(-c*t) (Sampaio, 1988). Potencial máximo de degradação (A), taxa de degradação da fração "B" (c), frações solúveis (S) e tempo de colonização $(\mathrm{TC})$ oriundo da equação TC $=-(1 / \mathrm{c}) *\left(\log _{\mathrm{n}}((\mathrm{A}-\mathrm{S}) / \mathrm{B})\right)$.

${ }^{2} \mathrm{DEf}=\mathrm{S}+((\mathrm{B} * \mathrm{c}) /(\mathrm{c}+\mathrm{k}))$.

Os potenciais máximos de degradação (A) da MS, que representa os valores da fração solúvel e insolúvel, mas potencialmente degradável, foram semelhantes entre caprinos e ovinos. Apesar dessa semelhança entre as espécies para o valor de A, houve maior diferença para a taxa de degradação (c), sendo observado maior valor em ovinos que em caprinos. Isso faz com que a curva de degradação, que representa a fermentação ruminal, seja superior em ovinos (Fig. 1). Segundo Sampaio (1994), os valores de c em feno de gramíneas tropicais variam de $3,0 \% / \mathrm{h}$ a $5,0 \% / \mathrm{h}$. Considerando-se esse intervalo, o valor de c do BCA em caprinos foi abaixo da média para volumosos tropicais. Martins et al. (2007) observaram em bovinos c de $4,63 \% / \mathrm{h}$ do BCA próxima a ovinos neste ensaio, corroborando também o efeito de espécies sobre os valores de c. O baixo valor de c em caprinos resultou em menor degradabilidade efetiva (DEf) da MS em todas as taxas de passagens consideradas: 2,6 e $8 \% / \mathrm{h}$.

O baixo valor observado para a fração solúvel (S) em água da MS do BCA é característico de alimentos fibrosos, uma vez que os componentes da parede celular são insolúveis em água.
Resultado semelhante foi observado por Carvalho et al. (2007), que observaram valor de $10,05 \%$ para a fração solúvel do BCA.

O tempo de colonização (TC) ou lag time da MS observado ficou fora dos valores normalmente observados para alimentos fibrosos de baixa qualidade. Esse tempo corresponde àquele para que as bactérias colonizem o substrato para o posterior fracionamento (Miron et al., 2001), portanto, quanto mais prolongado, mais tardio será o início da degradação do alimento. Assim, alimentos fibrosos de baixa qualidade, como o BCA, apresentam maior resistência à degradação, podendo apresentar TC mais longo. Borges (2000), no entanto, encontrou TC do BCA auto-hidrolisado bastante divergente em ovinos alimentados com $64,0 \%$ de BCA autohidrolisado $+36,0 \%$ de caroço de algodão integral, de $-4 \mathrm{~h} 33 \mathrm{~min}$, efeito semelhante ao TC para caprinos nesta pesquisa; e quando forneceu $14,0 \%$ de BCA auto-hidrolisado $+36,0 \%$ de caroço de algodão integral $+50,0 \%$ de feno de aveia (após o estádio de florescimento), observou TC de 9 h29min. 


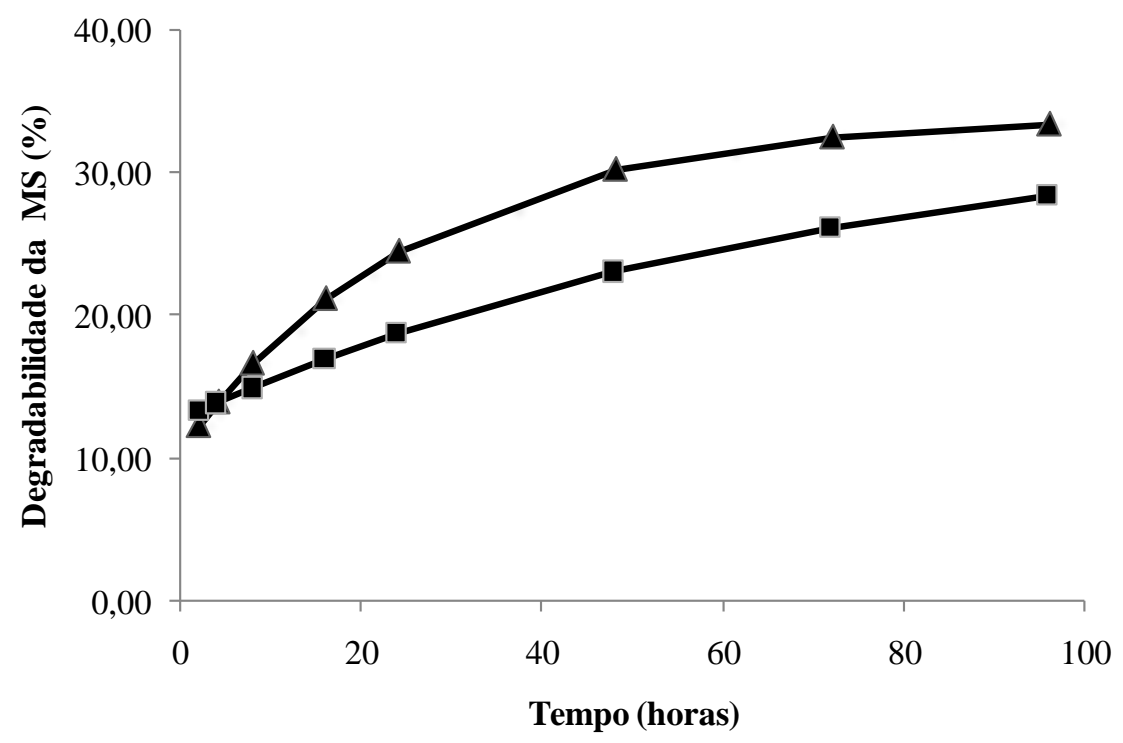

-A Ovinos: $\operatorname{Deg}=34,15-23,47 \operatorname{EXP}(-0,0373 * \mathrm{t}) \mathrm{TC}=0,52$
$-\boldsymbol{-}-$ Caprinos: $\operatorname{Deg}=35,08-21,38 \operatorname{EXP}(-0,0138 * \mathrm{t}) \mathrm{TC}=-2,8$

Figura 1. Degradabilidade ruminal da matéria seca (MS) do bagaço de cana-de-açúcar em ovinos e caprinos. Deg: degradabilidade (\%); t: tempo de incubação (h); TC: tempo de colonização.

Em relação à fração FDN, a espécie caprina apresentou maior valor de $\mathbf{A}$ em relação aos ovinos. Por outro lado, foi observado efeito semelhante ao da MS para c, sendo observada



$\rightarrow-$ Caprinos: $\operatorname{Deg}=33,82-25,93 \operatorname{EXP}(-0,0163 * \mathrm{t}) \mathrm{TC}=-0,49$ menor fração c da FDN em caprinos comparados a ovinos. Isso também explica uma curva de degradação (Fig. 2) mais acentuada em ovinos para FDN após 20 horas de incubação ruminal.

Figura 2. Degradabilidade ruminal da fibra em detergente neutro (FDN) do bagaço de cana-de-açúcar em ovinos e caprinos. Deg: degradabilidade (\%); t: tempo de incubação (h); TC: tempo de colonização. 
O elevado teor de lignina presente na FDN (Tab. 2) do BCA explica os baixos valores das frações A e c, portanto evidencia-se a baixa disponibilidade ruminal da FDN e menor utilização de sua energia, principalmente em caprinos, por estes terem apresentado menor c. Os baixos valores para DEf em caprinos reforçam essa observação. Utilizando bovinos, Martins et al. (2007) obtiveram potencial de degradação de $31,33 \%$ e DEf $2 \%$ /h de $22,54 \%$ da FDN do BCA semelhante ao desta pesquisa para ovinos.

O TC da fração FDN foi baixo, como observado para MS. Esses valores observados são atípicos, uma vez que alimentos fibrosos de baixa qualidade são mais resistentes à degradação ruminal, o que pode contribuir para o efeito de repleção ruminal do BCA em caprinos e ovinos.

A fração solúvel (S) foi bastante reduzida, devido à elevada concentração de celulose e lignina presentes na FDN (Tab. 2). A baixa solubilidade da celulose em água é resultante do tipo de ligação $(\beta 1 \rightarrow 4)$ que forma esses polímeros (Ahmed, 2003).

Não houve diferença $(\mathrm{P}>0,05)$ de $\mathrm{pH}$ ruminal entre as espécies (Tab. 6). Estes valores encontram-se bem próximos da faixa ideal de $\mathrm{pH}$ para máximo crescimento microbiano. Segundo Van Soest (1994), a faixa de $\mathrm{pH}$ para que haja atividade microbiana normal no rúmen é de $6,7 \pm 0,5$, e valores abaixo de 6,2 diminuem a taxa de digestão e aumentam o tempo de colonização para a degradação da parede celular. A relação volumoso:concentrado 53,56:46,44 nesta pesquisa favoreceu um $\mathrm{pH}$ ruminal mais estável para degradação de alimentos volumosos, uma vez que dietas com maior proporção de volumosos oscila os valores de $\mathrm{pH}$ próximos da neutralidade (Magalhães et al., 2006; Rabelo et al., 2008).

A concentração de $\mathrm{N}-\mathrm{NH}_{3}$ (Tab. 6) no líquido ruminal diferiu $(\mathrm{P}<0,05)$ entre e dentro de espécie. A maior concentração de $\mathrm{N}_{-}-\mathrm{NH}_{3}$ ruminal foi observada nos caprinos no tempo zero. Essa espécie apresentou, em todos os horários, exceto às duas horas, concentração de amônia superior aos ovinos. A maior permeabilidade do epitélio ruminal à ureia (Houpt e Houpt, 1968) e a maior glândula parótida, como proporção do peso vivo
(National..., 2007), em caprinos, resultam em maior quantidade de ureia reciclada.

Tabela 6. pH e concentração de nitrogênio amoniacal ruminal $\left(\mathrm{N}-\mathrm{NH}_{3}\right)$ em caprinos e ovinos nos tempos zero, seis e 12 horas após a primeira refeição

\begin{tabular}{|c|c|c|}
\hline & \multicolumn{2}{|c|}{ Espécie } \\
\hline & Caprina & Ovina \\
\hline Tempo (horas) & \multicolumn{2}{|c|}{$\mathrm{pH}$ ruminal } \\
\hline 0 & $6,88 \mathrm{Aa}^{*}$ & $6,89 \mathrm{Aa}$ \\
\hline 6 & $6,33 \mathrm{Ab}$ & $6,43 \mathrm{Aa}$ \\
\hline \multirow[t]{2}{*}{12} & $6,05 \mathrm{Ab}$ & $6,30 \mathrm{Aa}$ \\
\hline & \multicolumn{2}{|c|}{ N-NH3 (mg/dL) } \\
\hline 0 & $15,04 \mathrm{Aa}$ & $9,31 \mathrm{Ba}$ \\
\hline 6 & $5,18 \mathrm{Ab}$ & $3,82 \mathrm{Ab}$ \\
\hline 12 & $6,94 \mathrm{Ab}$ & $8,65 \mathrm{Aa}$ \\
\hline
\end{tabular}

*Letras diferentes, maiúsculas na linha e minúsculas na coluna, diferem entre espécies e tempos, respectivamente, pelo teste de Duncan $(\mathrm{P}<0,05)$.

Tanto caprinos quanto ovinos apresentaram maiores valores de $\mathrm{N}-\mathrm{NH}_{3}$ ruminal no tempo zero. Quando são fornecidas fontes de proteína verdadeira ao animal, um pico na concentração de $\mathrm{N}-\mathrm{NH}_{3}$ ruminal pode ser observado entre três e cinco horas após a alimentação. Assim, o longo intervalo entre as coletas no presente trabalho (seis horas) pode ter contribuído para a não observação de pico na concentração de $\mathrm{N}-\mathrm{NH}_{3}$ ruminal. A concentração mínima de $\mathrm{N}-\mathrm{NH}_{3}$ ruminal observada nas espécies caprina e ovina manteve-se próxima do valor mínimo de 5,0mg $\mathrm{N}-\mathrm{NH}_{3} / \mathrm{dL}$ de conteúdo ruminal para máximo crescimento microbiano, recomendado por Satter e Slyter (1974).

\section{CONCLUSÕES}

A dieta utilizada não comprometeu a fermentação ruminal, proporcionando um ambiente adequado para a degradação de alimentos fibrosos. Nesse aspecto, os ovinos mostraram maior velocidade de degradação da MS e da FDN, o que resultou em melhor utilização do BCA nessa espécie.

\section{AGRADECIMENTOS}

Os autores agradecem ao Plano de Aceleração do Crescimento da Embrapa (PAC-Embrapa), pelo suporte financeiro do trabalho (projeto número 03.08.04.004.00). 


\section{REFERÊNCIAS}

ASSOCIATION OF OFFICIAL ANALYTICAL CHEMISTS - AOAC. Official methods of analysis. 16.ed. Washington: AOAC, 1995. 2000p.

AHMED, S.; QURRAT-UL-AIN; ASLAM, N. et al. Induction of xylanase and cellulose genes from Trichoderma harzianum with different carbon sources. Pak. J. Biol. Sci., v.6, p.19121916, 2003.

BORGES, I.; GONÇALVES, L.C.; MORAIS, M.G. et al. Influencia da dieta sobre o desaparecimento in situ da matéria seca, da matéria orgânica e da fibra em detergente neutro do bagaço de cana-de-açúcar auto-hidrolisado. Arq. Bras. Med. Vet. Zootec., v.52, p.235-242, 2000.

CARNEIRO, J.C. Dinâmica da fermentação ruminal e cecal em ovinos e caprinos. 1994. 143 f. Tese (Doutor em Ciência Animal) Universidade Federal de Minas Gerais, Belo Horizonte.

CARNEIRO, J.C.; RODRIGUEZ, N.M.; GONÇALVES. Consumo, digestibilidade aparente e balanço de nitrogênio em ovinos e caprinos alimentados com palha de soja. Arq. Bras. Med. Vet. Zootec., v.50, p.717-720, 1998.

CARVALHO, G.G.P.; PIRES, A.J.V.; SILVA, R.R. et al. Degradação ruminal do bagaço de cana-de-açúcar tratado com ureia. Arch. Zootec., v.56, p.59-62, 2007.

CUNHA, I.S.; BARRETO, C.C.; COSTA, O.Y.A. et al. Bacteria and Archaea community structure in the rumen microbiome of goats (Capra hircus) from the semiarid region of Brazil. Anaerobe, v.17, p.118-124, 2011.

GARCÍA, M.A.; AGUILERA, J.F.; MOLINA ALCAIDE, E. Voluntary intake and kinetics of degradation and passage of unsupplemented and supplemented pastures from semiarid lands in grazing goats and sheep. Livest. Prod. Sci., v.44, p.245-255, 1995.

HOUPT, T.R.; HOUPT, K.A. Transfer of urea nitrogen across the rumen wall. Am. J. Physiology, v.214, p.1296-1303, 1968.
MAGALHÃES, A.L.R.; CAMPOS, J.M.S.; CABRAS, L.S. et al. Cana-de-açúcar em substituição à silagem de milho em dietas para vacas em lactação: parâmetros digestivos e ruminais. Rev. Bras. Zootec., v.35, p.591-599, 2006.

MARTINS, A.S.; VIEIRA, P.F.; BERCHIELLI, T.T. et al. Degradabilidade in situ e observações microscópicas de volumosos em bovinos suplementos com enzimas fibrolíticas exógenas. Rev. Bras. Zootec., v.36, p.1927-1936, 2007.

McDONALD, J. A revised model for the estimation of protein degradability in the rumen. J. Agric. Sci., v.96, p.251-252, 1981.

MEHREZ, A.Z.; ØRSKOV, E.R. A study of the artificial fibre bag tecnhique for determing the digestibility of feed in the rumen. J. Agric. Sci., v.88, p.645-650, 1977.

MIRON, J.; BEN-GHEDALIA, D.; MORRISON, M. Invited Review: Adhesion mechanisms of rumen cellulolytic bacteria. $J$. Dairy Sci., v.84, p.1294-1309, 2001.

MORAND-FEHR, P. Recent developments in goats nutrition and application: A review. Small Rumin. Res., v.50, p.25-43, 2005.

NATIONAL Research Council - NRC. 1.ed. Washington, DC, USA: NAP, 2007, 362p.

ØRSKOV, E.R.; McDONALD, J. The estimation of protein degradability in the rumen fromincubation measurements weightes according to rate of passage. J. Agric. Sci., v.92, p.499-503, 1979.

PFISTER, J.A.; MALECHEK, J.C. The Voluntary forage intake and nutrition of goats and sheep in the semiarid tropics of Northeastern Brazil. J. Anim. Sci., v.63, p.1078-1086, 1986.

PINTO, A.P.; PEREIRA, E.S.; MIZUBUTI, I.Y. Características nutricionais e formas de utilização da cana-de-açúcar na alimentação de ruminantes. Semin-Cienc. Agrar., v.24, p.73-84, 2003.

PIRES, A.J.V.; REIS, R.A.; CARVALHO, G.G.P. et al. Bagaço de cana-de-açúcar tratado com hidróxido de sódio. Rev. Bras. Zootec., v.35, p.953-957, 2006. 
RABELO, M.M.A.; PIRES, A.V.; SUSIN, I. et al. Digestibilidade dos nutrientes e parâmetros ruminais de bovinos de corte alimentados com rações contendo bagaço de cana-de-açúcar obtido pelo método de extração por difusão ou por moagem convencional. Rev. Bras. Zootec., v.37, p.1696-1703, 2008.

SAMPAIO, I.B.M. Experimental designs and modelling techniques in the studies of roughage degradation in rumen and growth of ruminants. 1988. 214f. Tese (Doutorado em Fisiologia) Univestity of Reading, Reading.
SAMPAIO, I.B.M. Contribuições estatísticas e de técnica experimental para ensaios de degradabilidade de forragens quando avaliada in situ. In: REUNIÃO ANUAL DA SOCIEDADE BRASILEIRA DE ZOOTECNIA, 31., 1994, Maringá. Anais..., Maringá: Sociedade Brasileira de Zootecnia, 1994, p.81-88.

SATTER, L.D.; SLYTER, L.L. Effect of ammonia concentration on rumen microbial production in vitro. Brit. J. Nutr., v.32, p.199208, 1974.

STATISTICAL ANALYSIS SYSTEMS - SAS. SAS/onleineDoc ${ }^{\circledR}$. Versão 9.2. Cary: 2009.

VAN SOEST, P.J. Nutritional ecology of the ruminant, Ithaca: Cornell University Press. 1994. 476p. 